\title{
An Empirical Research on FPAD Pedagogy in College English Class
}

\author{
Ying Chen \\ Zhejiang Yuexiu University, Shaoxing, China \\ Email: yinglimiao@126.com
}

How to cite this paper: Chen, Y. (2021) An Empirical Research on FPAD Pedagogy in College English Class. Open Access Library Journal, 8: e7633.

https://doi.org/10.4236/oalib.1107633

Received: June 10, 2021

Accepted: September 23, 2021

Published: September 26, 2021

Copyright (C) 2021 by author(s) and Open Access Library Inc.

This work is licensed under the Creative Commons Attribution International License (CC BY 4.0).

http://creativecommons.org/licenses/by/4.0/

\section{(c) (i) Open Access}

\begin{abstract}
Based on Flipped class and developed as a unity of both Blended Class and PAD Class (Presentation-Assimilation-Discussion), FPAD pedagogy is a new teaching model applied in College English for research and exploration. It is a procedure for English teachers to improve teaching methods, plan reasonable teaching processes and rebuild teaching system. Based on PAD class, and implementing both the flipped classroom and blended learning, FPAD pedagogy rationally arranges the learning activities online and offline alike to improve teaching effects, enhance students' participation and promote the transformation of high-level learning results. FPAD pedagogy aims to cultivate students' core competencies, and allows students to grow into learning, critical, questioning, diligent, practical and creative talents.
\end{abstract}

\section{Subject Areas}

Language Education

\section{Keywords}

College English, Flipped Class, PAD, FPAD

\section{FPAD教学研究背景}

面对零零后学生的个性, 现代化教育技术的冲击和始料未及的疫情突袭, 教师们不得不面对教学过程中不断凸显的 “痛点”。大学外语教学中, 学生 常常因为学习驱力不足而产生解怠, 认为对非英语专业的学生来说, 外语能 力的高低并不会对未来的就业和生存产生至关重要的影响; 自主学习能力较 弱; 英语学习缺乏阶段性目标; 学习缺乏规划和动力等。如果教师不及时做 出适时的教学实践革新, 那么这些 “痛点” 无疑将会转化成学生口中的 “槽 点”。而互联网 + 教育背景下, 时代要求教师应具备整合技术的学科教学知 
识(Technological Pedagogical and Content Knowledge), 并以成为 “TPACK” 型教师为目标 [1], 能够教科学地将理论基础与课堂实践融合, 借助技术手段, 改进教学手段, 完善教学设计, 重构教学体系。

翻转课堂(Flipped Class)是近年来教育领域的热门话题, 这一教学模式颠 倒了传统的教学过程, 将部分较为基础的知识安排在课前学生自主学习, 课 中则注重教师的答疑解惑和师生的交流探讨。这样的教学安排, 一方面将学 生的课堂被动学习转变为课后主动探索, 教师也从教学主导者转变为引导者。

对分课堂(PAD) 是由复旦大学张学新教授(2013)针对当下的教学“痛点”, 同时基于四元理论提出的新型教学范式。PAD 教学将课堂教学一分为二, 既 注重传统教学中的教师讲授, 又鼓励和促成学生的自主学习能力培养和学生 独学能力的锻炼。其核心教学环节主要包括教师精讲, 学生内化, 小组讨论, 教师答疑四个环节 [2]。此外, PAD 教学还提出了 “亮考帮”, 精讲留白等教 学活动, 同时发挥了传统教学和 “互联网+” 背景下创新教学的优势, 取长补 短, 具有较强的普适性和创新性。

《大学英语教学指南》(2017)指出: 大学外语教育是我国高等教育的重要 组成部分, 对于促进大学生知识、能力和综合素质的协调发展具有重要意义。 大学英语作为大学外语教育的最主要内容, 是大多数非英语专业学生在本科 教育阶段必修的公共基础课程。其重要性可见一斑。而 FPAD 教学则为解决 实践教学中出现的这些 “痛点” 提供了新的思路。在教学实践中, 各方学者 们对于大学外语教学的研究和探索层出不穷。其中不乏外语教师对大学外语 教学的创新和思考。而近两年改革创新的关键词则主要涉及了 “翻转课堂” 、

“混合式教学”、“数字化教学”、“BOOPS 教学设计”和 “对分课堂” 等。 而在过去近两年的时间里, 笔者同团队教师一起开展了的基于翻转课堂的大 学英语混合式对分教学(FPAD), 将对分课堂进行了校本化调整, 实现了大学 英语混合式对分的教学探索。FPAD 教学在对分课堂的基础上, 加入了翻转 课堂, 并利用翻转课堂进一步优化了对分课堂的教学进程, 合理地配置教学 资源和重构教学内容, 进一步提高了学生课内外的参与度, 科学规划了线上 线下学习和学时分配, 促成了教学相长的双赢课堂的构建。通过 FPAD 教学, 笔者及教学团队旨在改善教学现状, 通过教学创新和教学改革, 促进学生成 长成才, 帮助让学生成长为乐学善学, 批判质疑, 勤学反思, 实践创新的应 用型人才。在教学过程中, 我们基于支架理论、动机理论和学习环境四元理 论等开展创新教学, 一方面帮助教师缓解了课程设计和教学互动的焦虑, 另 一方则解决了学生目前在翻转课堂和对分课堂学习过程中学习任务重, 内驱 力疲乏的窘境。

\section{2. 教学实践过程}

\section{1. 教学研究对象}

FPAD 教学研究主体为浙江越秀外国语学院, 中国语言文化学院, 汉语 言文学 1903 班和 1904 班学生, 共计 77 人。该研究群体英语基础普遍较为薄 弱, 尤其是英语听说能力, 且英语学习内驱力不足。所以在课堂上, 学生们 
相继展现出了厌学急学的一面: 学习主动性差, 抱怨学习任务繁重, 课堂互 动仅有为数不多的学生参与, 且不善于整理分析学习资料等。

\section{2. 研究过程(Pedagogical Planning)}

FPAD 教学是基于翻转课堂、对分课堂和混合式教学理念, 重构教学设 计和教学实践的过程。FPAD 的教学设计, 采用翻转课堂, 对分课堂和混合 式教学, 主要包含了线上 “四步走” 和线下 “四阶段”。线上含主题内容学 习, 自主测试, 线上讨论, 文化及技能拓展等内容; 线下则包括阶段 1 (背景 知识及文章结构梳理, 含读写技巧等), 阶段 2 (重难点知识解析), 阶段 3 (小 组讨论和 “亮考帮” ), 阶段 4 (成果分享及答疑)。同时课程评价以 “ $\mathrm{OBE”}$ 理念为指导, 对学生学习成果开展含知识目标, 技能目标, 思政目标的多元 化过程性评价。

具体教学过程为(某单元为例): 在第一阶段, 线上学生自主学习主题相 关地背景知识, 线下则在教师指导下完成文章结构的梳理, 掌握读写技巧和 阅读文章大意; 第二阶段, 学生学习和内化重难点知识。线上学生根据教师 的视频和文本资料, 学习较为简单和基础的语言点和词汇知识。课堂上则以 老师和同伴为支架, 通过教师精讲和同伴讨论完成重难点知识的学习; 第三 阶段, 学生运用所学, 参与课堂 “亮考帮” 的讨论, 即 “亮闪闪 - 考考你 帮帮我”, 这也是对分课堂的亮点。“亮” 是指分享所学内容中的金句和亮 点, “考” 则是学生在组内互相考察知识点的掌握和理解, 而 “帮” 则是组 内互相帮助解答疑难问题等。第四阶段, 即最后一次课则以学生的成果展示 和文化技能拓展练习和答疑为主。教师将先组织学生对其成果进行展示, 组 间开展互评, 然后将本单元所学的文化和知识技能进行答疑和讲解。课程学 习最后, 学生会在教师指导下完成单元学习反思, 内化巩固单元所学。

\subsection{FPAD 教学研究结果}

FPAD 教学实践历时两年, 循序渐进, 教学进程符合学生的学习规律和 课程教学要求。本次教学改革的教学结果也得到了学生的认可和反馈。在大 学英语课程即将结束之际, 笔者对研究对象汉语言文学 1903 班和汉语言文学 1904 班共计 77 位学生开展了 “基于翻转课堂的大学英语混合式对分(FPAD) 教学效果” 问卷调查。本次问卷主要基于两年 FPAD 教学实践过程, 依次设 计了学生对对分课堂, 混合式教学以及混合式对分的学习体验反馈。同时问 卷还注重了解学生在学习过程中学习行为的变化, 包括自主学习, 小组合作, 亮考帮活动和思政体验等。共计 77 位学生参与了问卷调查, 且收到有效问卷 77 份。其问卷结果分析如下:

在反馈中, 同学们认为 FPAD 教学使得知识呈现方式多样化, 不限于板 书、 $\mathrm{PPT}$ 等传统的教学手段和教学资源; 基于翻转课堂的混合式教学模式让 学生自主学习能力得到了提高, 学习方式和学习效率也得到了相应的改善;

FPAD 教学方式新颖, 有效地激发了学生学习的兴趣和积极性; 而对分课堂 的学习更是提高了同学们的参与度且四元教学即 “讲授 - 内化 - 讨论 - 答疑” 的教学过程, 符合学生们自身的学习规律, 让学习事半功倍。这样的反馈和 
教学效果与其他对分课堂和混合式教学改革学者的实践研究保持一致。

此外, 同学们还表示, 在大学英语学习中, 线上学习, 对分课堂, 翻转 课堂的有机融合, 适应了不同学生的学习需求, 让自己的外语学习变得更加 积极了; 学习效率也较以往有了很大的提高。在知识的掌握上, $71 \%$ 的同学 认为能够消化吸收 $60 \%$ 以上的知识点(其中 $19.5 \%$ 的同学认为吸收率可以达到 $80 \%$ 以上); $26 \%$ 的同学则只能吸收 $40 \%$ 60\%左右。通过进一步调查影响学生 掌握知识点的原因, 发现主要涉及以下 2 个方面: 一、课业重, 分身乏术, 难以同时学习多科目的教学内容; 二、教学内容(教材)超出了自身的接受范 畴。

最后在课堂满意度调查上, 78.1\%的同学给予了课程 FPAD 学习体验 8 分 以上的评价, 另外 $21.9 \%$ 的同学则给了 $5 \sim 7$ 分的评价 (5 分 $6.5 \% ; 6$ 分 3.9\%; 7 分 $10.4 \%)$ 。总体来说, 教学效果得到了绝大多数同学的肯定和支持。

为了进一步验证 FPAD 的教学效果, 笔者还对同专业采用混合式教学的 汉语言文学 1901 和 1902 班开展了 “大学英语混合式教学效果” 问卷调查, 后者有效问卷为 45 份。在对问卷开展对比研究后, 问卷分析结果如表 1 所示:

在学习态度变化上, FPAD 学生以 “态度改变”, “学习积极” 为高频 描述词, 相较于混合式教学的学生(17.78\%), 绝大多数同学 $(48.05 \%)$ 认为自己 在参与 FPAD 学习后, 学习态度发生了变化, 变得更加积极, 更加自主了。 而变得懒散的同学占比约为 $5.59 \%$, 低于对照班级的 $22.22 \%$ 。可见多数学生 认识到了独学的重要性, 开始培养和进一步提升自己的自主学习能力, 而这 一点也在后面的关于独学行为变化以及学习效率评价选项分析中得到了验 证。

通过对比, 笔者还发现: 在所有学习活动中, 双方学生都给予了课内外 听说任务, 教师指导下的视听说技能训练, 教师精讲高度关注, 认为通过这 些传统的教学活动能够有效地帮助自己。可见中国学生对于传统课堂和线下 课堂的重视。但是在独学和小组讨论等方面, FPAD 教学下的学生 $(44.16 \%$, $53.25 \%)$ 则认为获益更多, 远远超过了混合式教学下学生 $(26.67 \%, 11.11 \%)$ 的 选择。可见, FPAD 可以较好地激发学生的独学兴趣, 参与讨论学习和小组 学习。同样, 之后关于学习收获的调查选项中, 也体现了这一差异。FPAD 教学下的学生普遍认为在学习中锻炼了社交, 思考和自主学习能力, 其比例 $50.65 \%$ 也高于后者 $26.67 \%$ 。而不可否认的是, 无论是自主学习能力, 社交能 力, 批判性思维, 还是合作能力和领导力, 都是学生未来工作和生活中所必 须具备的软实力。

表 1. FPAD 教学与混合式教学效果对比

\begin{tabular}{cccc}
\hline & & FPAD (\%) & Blended Learning (\%) \\
\hline 学习态度变化 & 变得积极 & $48.05 \%$ & $17.78 \%$ \\
& 变得懒散 & $5.59 \%$ & $22.22 \%$ \\
其他(不变、不确定) & $46.36 \%$ & $60 \%$ \\
\hline 能力培养 & 独学能力 & $44.16 \%$ & $26.67 \%$ \\
学习收获 & 合作能力 & $53.25 \%$ & $11.11 \%$ \\
\hline
\end{tabular}


最后, 在大学英语 $\mathrm{FPAD}$ 和混合式学习体验的评价中, 同学们都予以了 肯定和好评, 对教学改革和创新的效果表示满意。在学习体验和收获评分中, 前者平均分为 8.3 分, 后者 7.44 分。

当然, 在经历了 $\mathrm{FPAD}$ 学习后的学生们还表示, 学习中也遇到了很多问 题, 影响了自身的学习体验, 例如教学平台功能或者技术不够完善; 网络信 号的影响; 周围影响学习的干扰因素太多; 线上学习缺乏监督, 容易解急; 线上资源不丰富, 缺乏趣味性; 学习任务重等。而这些的反馈, 对于教师进 一步提升教学方法, 完善教学资源提供了新的思路和激励。但是总体而言, 基于 FPAD 教学模式的大学英语混合式对分课堂, 是师生 “用智, 用情, 用 心” 构建的良性生态课堂。FPAD 教学将传统课堂和创新课堂并重, 符合当 代大学生的学习需求和中国教育发展的新趋势。

\section{FPAD的教学特色}

FPAD 教学, 融合了先进教学理念, 是符合本国国情的本土化课堂。混 合式对分课堂保留了传统教学中的讲授法和讨论法, 但是通过科学合理的时 间分配, 改善了讲授法带来的 “教师过分权威” , 讨论法中 “秩序混乱”、

“缺乏支架” 等问题, 构建了线上、线下, 学生, 教师, 教室的良性生态课 堂。

（一）教师、学生、平台实现了四维多元化互动。异于传统课堂的 “教师 学生 - 教室的三维互动生态体系”, 互联网+背景下的混合式教学将线上学习 和互动平台也纳入了教学生态中。形成了 “教师 - 学生 - 平台 - 教室四维多 元化互动生态体系” 。例如笔者的大学英语教学就借助了智慧树平台, 架起 了师生之间多渠道沟通和学习的桥梁。

(二) 常态化的过程性学习让学生自主学习能力得到了显著的提高, 实现 了个性化学习。信息化时代, 在线学习资源与课程日新月异。而《大学英语 教学指南(送审稿)》顺应了时代的要求指出: “各高校应充分利用信息技术, 积极创建多元的教学与学习环境, 鼓励教师建设和使用微课、慕课, 利用网 上优质教育资源改造和拓展教学内容, 实施基于课堂的在线网上课程的翻转 课堂混合式教学模式, 使学生朝着主动学习、自主学习和个性化学习方向发 展[3]。”FPAD 混合式教学在合理安排了线上线下学习活动的同时, 为学生 提供了丰富的学习资源, 更有利于教师基于学情来因材施教。同时在课堂翻 转的情况之下, 学生需要自主完成部分内容的学习, 配合对分课堂的 “精讲 精练”、“少讲精讲”、“适当留白” 的原则, 完成线上线下自主学习。培 养了学生的独学能力。

(三) 讨论中, 学生合作学习的能力得到了提高; 团队协作中, 沟通、领 导力得到了锻炼。在 “FPAD” 教学中, 学生需要与团队成员一起完成各项任 务和讨论, 这既包含了当堂对分的小组讨论, 也包括隔堂对分的 “亮考帮” 和最后讨论环节的(个人或者团队)成果分享。在合作中培养学生们合作, 领 导, 沟通和社交等能力, 同时提高了班级凝聚力。

(四) 学生学习将知识学习和策略学习进行了有效结合, 促进教学活动高 阶目标的实现。教与学的过程中, 教师一改传统教学中填鸭式的单向授课模 
式, 将传统课堂, 翻转课堂与 “互联网+” 背景下的混合式对分课堂实现了较 为接地气的融合。注重 “授人以鱼” 的同时 “授人以渔”。例如教学中读写 技巧的讲授, 创新任务的布置, 都可以有效地将学生所学转变为学生的创新 性成果。

(五) 融合课程思政的大学英语课堂, 在中西文化对比学习中, 既拓展了 学生的国际视野, 也培养了学生跨文化听说读写能力和人文素养, 树立文化 自信，传承与发扬中国文化。

\section{4. 结语}

FPAD 教学实践极具 “互联网+” 特色的智慧教育, 能够在一定程度上同 时发挥教师和学生在学习中的作用, 即可以引导着学生学习行为和思维的改 变, 也可以让教师在教学和创新中发挥价值, 不断提升自身教学水平和专业 能力。FPAD 教学中, 课堂和学习变有趣了; 学生们变得更加有责任心了; 敢于挑战权威了; 抱怨变少了; 愿意合作了; 开口更主动了; 摈弃了偏见, 交流更自如了; 更善于归纳和演绎了。这些改变逐步激活了课堂, 成为了学 生学习体验中充满特殊意义的一笔。但是在本次教学改革实践中, 笔者和团 队教师们还发现, 当代大学生的外语学习积极性仍需进一步激发, 教学效果 评价与评估也应更趋于合理化和体系化。如何激发学生学习兴趣和动力，同 时制订科学的客观的教学效果评价标准, 建立合理普适的 FPAD 课程教学质 量评估细则是我们进一步思考和研究的方向。

\section{基金项目}

本文为 2019 年浙江省一流本科课程(线上线下混合式)《综合英语》, 及 2021 年浙江省高校课程思政教学研究项目 “一流课程建设背景下大学英语课 程思政内涵和实施路径探究”的阶段性研究成果。

\section{Conflicts of Interest}

The author declares no conflicts of interest.

\section{References}

[1] 何克抗. TPACK一一美国“信息技术与课程整合”途径与方法研究的新发展 (下)[J]. 理论探讨, 2012(6): 47-56.

[2] 张学新. 对分课堂: 大学课堂教学改革的新探索[J]. 复旦教育论坛, 2014(5): 5-10.

[3] 应洁琼, 宁强. 大学英语混合教学中合作学习与自主学习集成模式研究[J]. 教育 理论与实践, 2019(3): 45-47. 


\section{Appendix (Abstract and Keywords in Chinese)}

\section{基于翻转课堂的大学英语混合式对分教学模式研究}

摘要: 基于翻转课堂的大学英语混合式对分教学实践探索(Flipped-PAD), 源 于对翻转课堂(Flipped Class)和对分课堂(Pad Class)的教学思考, 是教师通过 改进教学手段, 合理规划教学进程, 重建教学体系的过程。实践中, 教师以 对分课堂( $\mathrm{PAD}$ )为依托, 借助翻转课堂和混合式教学(Blended Learning)的优 势, 重构教学设计。FPAD 教学进一步合理地安排线上线下教学, 促进和改 善教学效果, 提升学生学习参与度和高阶学习成果的转化, 培养学生的核心 素养, 让学生成长为乐学善学, 批判质疑, 勤学反思, 实践创新的应用型人 才。

关键词: 大学英语, 翻转课堂, 对分课堂, 混合式对分 